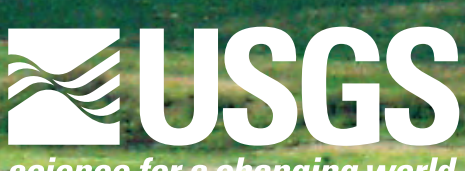

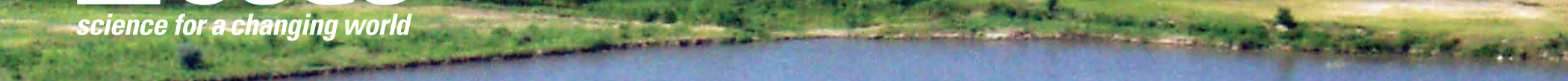

\title{
Objectives, Priorities, Reliable Knowledge, and Science-Based Management of Missouri River Interior Least Terns and Piping Plovers
}

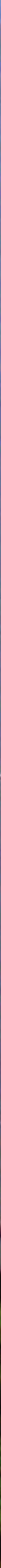

U.S. Department of the Interior U.S. Geological Survey 


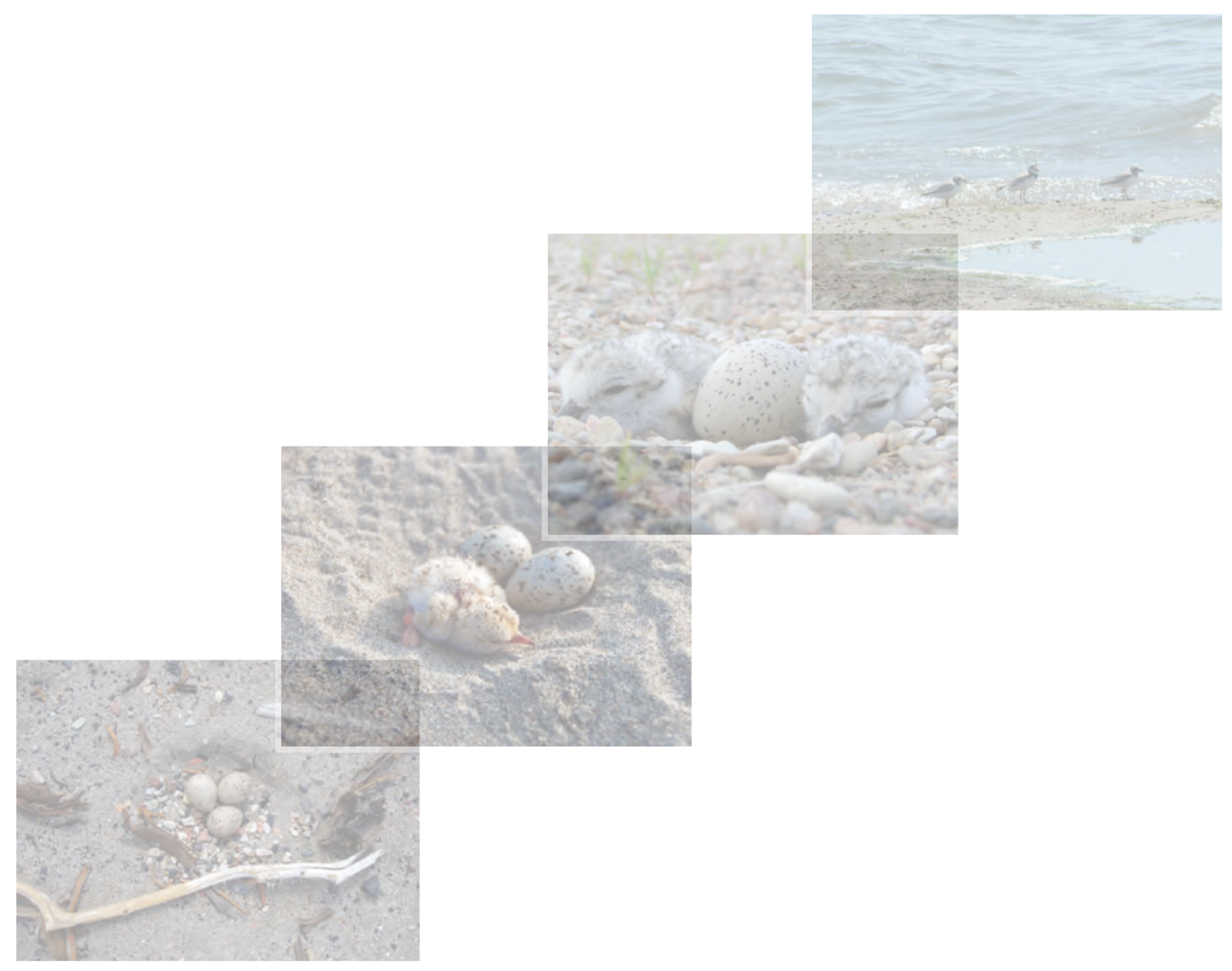

Cover. Background photo: Sandbar habitat on the Gavins Point Reach of the Missouri River, South Dakota. Inset photos (bottom left to top right): Least tern nest, Garrison Reach of the Missouri River, North Dakota. Newly hatched least tern chick, Gavins Point Reach of the Missouri River, South Dakota. Newly hatched piping plover chicks, Lake Sakakawea, North Dakota. Adult piping plover with two fledglings, Lake Sakakawea, North Dakota. 


\section{Objectives, Priorities, Reliable Knowledge, and Science-Based Management of Missouri River Interior Least Terns and Piping Plovers}

By Mark Sherfy, Michael Anteau, Terry Shaffer, Marsha Sovada, and Jennifer Stucker

Open-File Report 2011-1236 


\title{
U.S. Department of the Interior \\ KEN SALAZAR, Secretary \\ U.S. Geological Survey \\ Marcia K. McNutt, Director
}

\author{
U.S. Geological Survey, Reston, Virginia: 2011
}

For more information on the USGS - the Federal source for science about the Earth, its natural and living resources, natural hazards, and the environment, visit http://www.usgs.gov or call 1-888-ASK-USGS.

For an overview of USGS information products, including maps, imagery, and publications, visit http://www.usgs.gov/pubprod

To order this and other USGS information products, visit http://store.usgs.gov

Any use of trade, product, or firm names is for descriptive purposes only and does not imply endorsement by the U.S. Government.

Although this report is in the public domain, permission must be secured from the individual copyright owners to reproduce any copyrighted materials contained within this report.

Suggested citation:

Sherfy, M., Anteau, M., Shaffer, T., Sovada, M., and Stucker, J., 2011, Objectives, priorities, reliable knowledge, and science-based management of Missouri River interior least terns and piping plovers: U.S. Geological Survey Open-File Report 2011-1236, 26 p. 


\section{Contents}

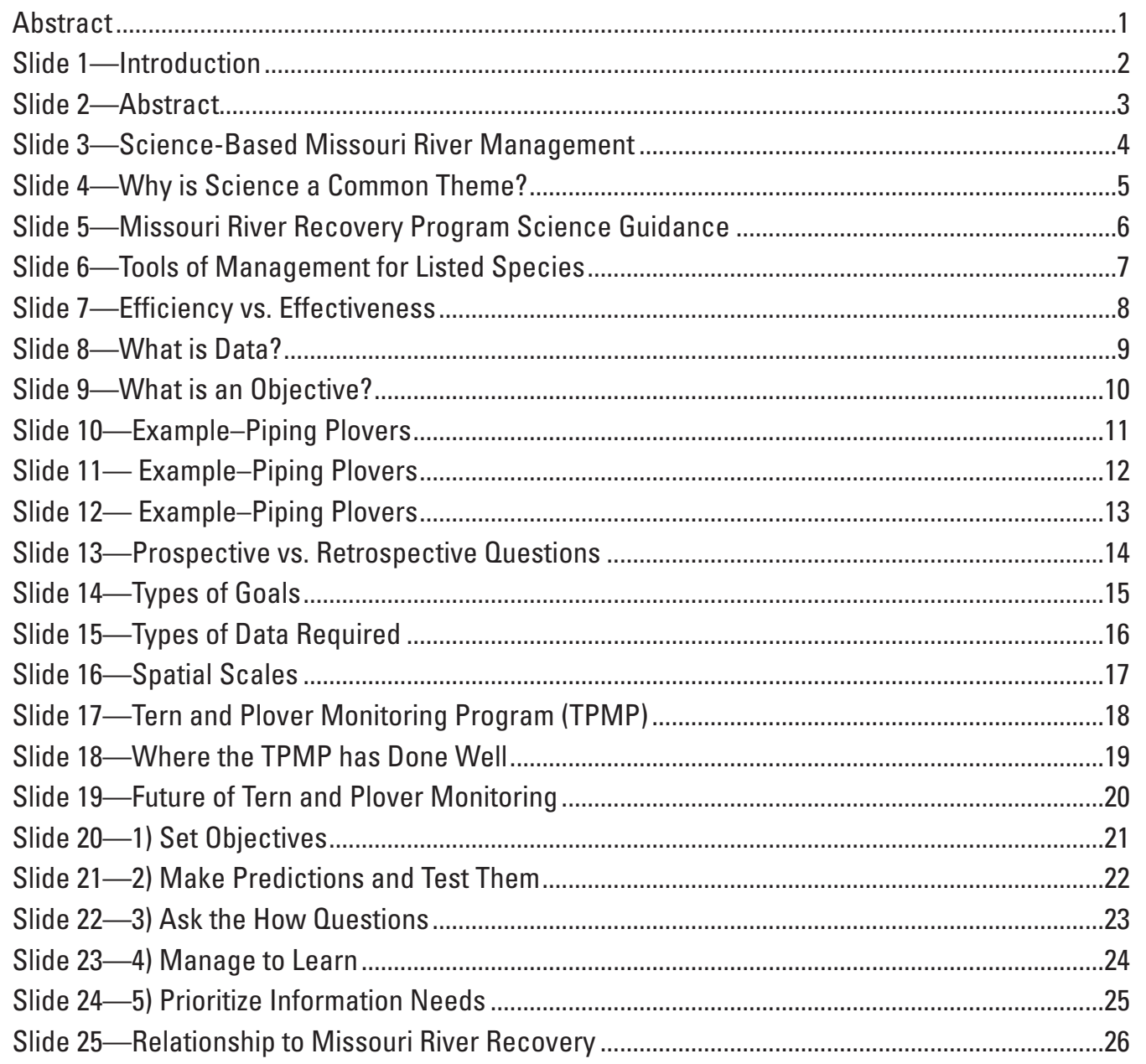





\title{
Objectives, Priorities, Reliable Knowledge, and Science- Based Management of Missouri River Interior Least Terns and Piping Plovers
}

\author{
By Mark Sherfy, Michael Anteau, Terry Shaffer, Marsha Sovada, and Jennifer Stucker
}

\begin{abstract}
Supporting recovery of federally listed interior least tern (Sternula antillarum athalassos; tern) and piping plover (Charadrius melodus; plover) populations is a desirable goal in management of the Missouri River ecosystem. Many tools are implemented in support of this goal, including habitat management, annual monitoring, directed research, and threat mitigation. Similarly, many types of data can be used to make management decisions, evaluate system responses, and prioritize research and monitoring. The ecological importance of Missouri River recovery and the conservation status of terns and plovers place a premium on efficient and effective resource use. Efficiency is improved when a single data source informs multiple high-priority decisions, whereas effectiveness is improved when decisions are informed by reliable knowledge. Seldom will a single study design be optimal for addressing all data needs, making prioritization of needs essential. Data collection motivated by wellarticulated objectives and priorities has many advantages over studies in which questions and priorities are determined retrospectively. Research and monitoring for terns and plovers have generated a wealth of data that can be interpreted in a variety of ways. The validity and strength of conclusions from analyses of these data is dependent on compatibility between the study design and the question being asked. We consider issues related to collection and interpretation of biological data, and discuss their utility for enhancing the role of science in management of Missouri River terns and plovers.

A team of USGS scientists at Northern Prairie Wildlife Research Center has been conducting tern and plover research on the Missouri River since 2005. The team has had many discussions about the importance of setting objectives, identifying priorities, and obtaining reliable information to answer pertinent questions about tern and plover management on this river system. The objectives of this presentation are to summarize those conversations and to share insights about concepts that could contribute to rigorous science support for management of this river system.
\end{abstract}




\section{Slide 1}

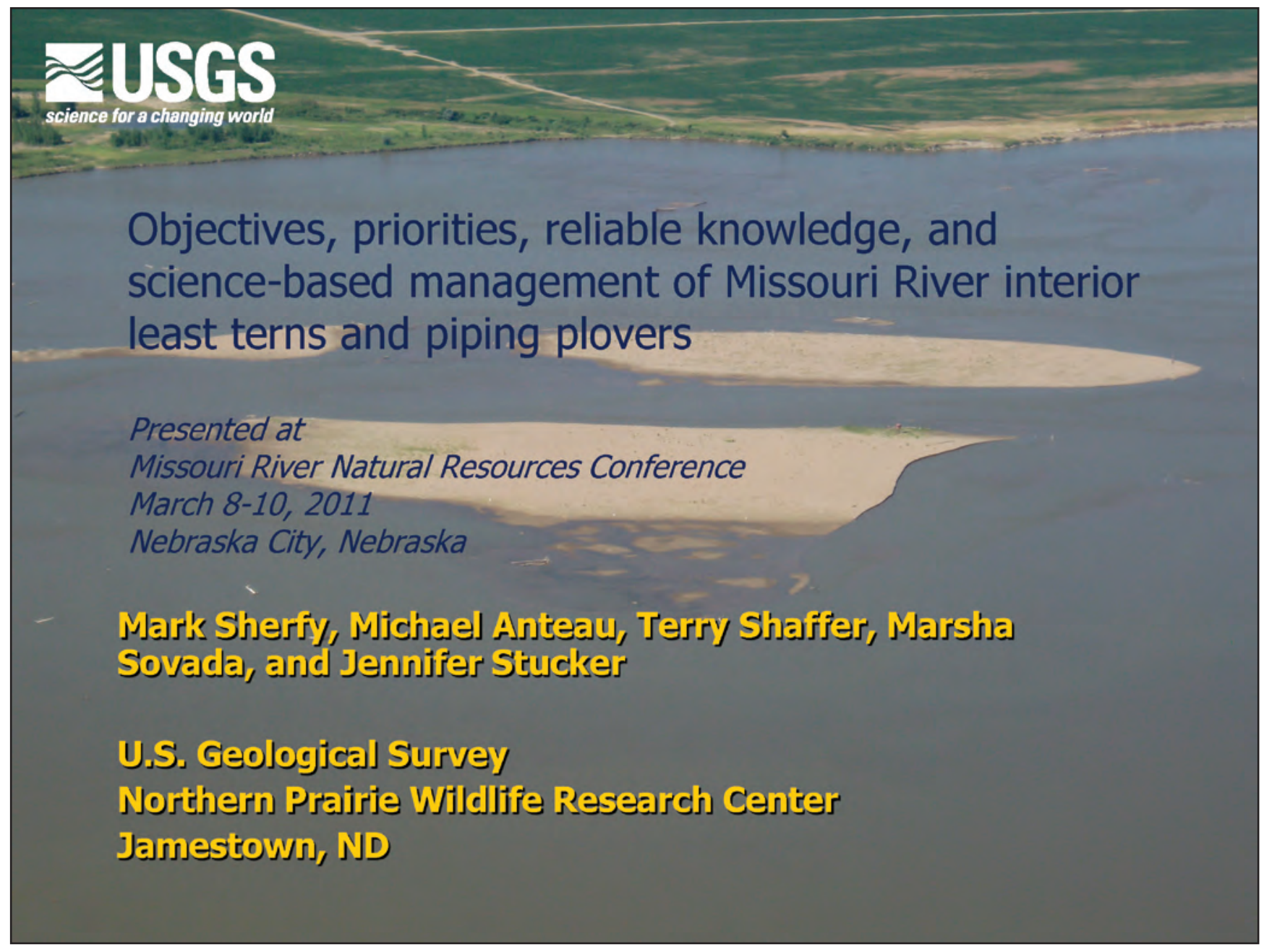




\section{Slide 2}

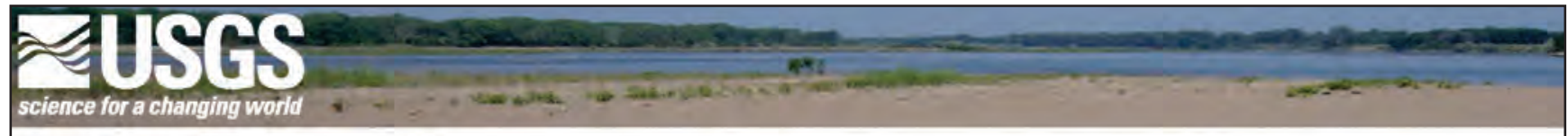

\section{Abstract}

Supporting recovery of federally listed interior least tern (Sternula antillarum; tern) and piping plover (Charadrius melodus, plover) populations is a desirable goal in management of the Missouri River ecosystem. Many tools are implemented in support of this goal, including habitat management, annual monitoring, directed research, and threat mitigation. Similarly, many types of data can be used to make management decisions, evaluate system responses, and prioritize research and monitoring. The ecological importance of Missouri River recovery and the conservation status of terns and plovers place a premium on efficient and effective resource use. Efficiency is improved when a single data source informs multiple high-priority decisions, whereas effectiveness is improved when decisions are informed by reliable knowledge. Seldom will a single study design be optimal for addressing all data needs, making prioritization of needs essential. Data collection motivated by well-articulated objectives and priorities has many advantages compared to studies in which questions and priorities are determined retrospectively. Research and monitoring for terns and plovers have generated a wealth of data that can be interpreted in a variety of ways. The validity and strength of conclusions from analyses of these data are dependent on compatibility between the study design and the question being asked. We consider issues related to collection and interpretation of biological data, and discuss their utility for enhancing the role of science in the management of Missouri River terns and plovers.

A team of U.S. Geological Survey scientists at Northern Prairie Wildlife Research Center has been doing tern and plover research on the Missouri River since 2005. The team has had many discussions about the importance of setting objectives, identifying priorities, and using the right information to answer pertinent questions about tern and plover management on this river system. The objectives of this presentation are to summarize those conversations and to share some insights about concepts that could contribute to rigorous science support for management of this river system. 


\section{Slide 3}

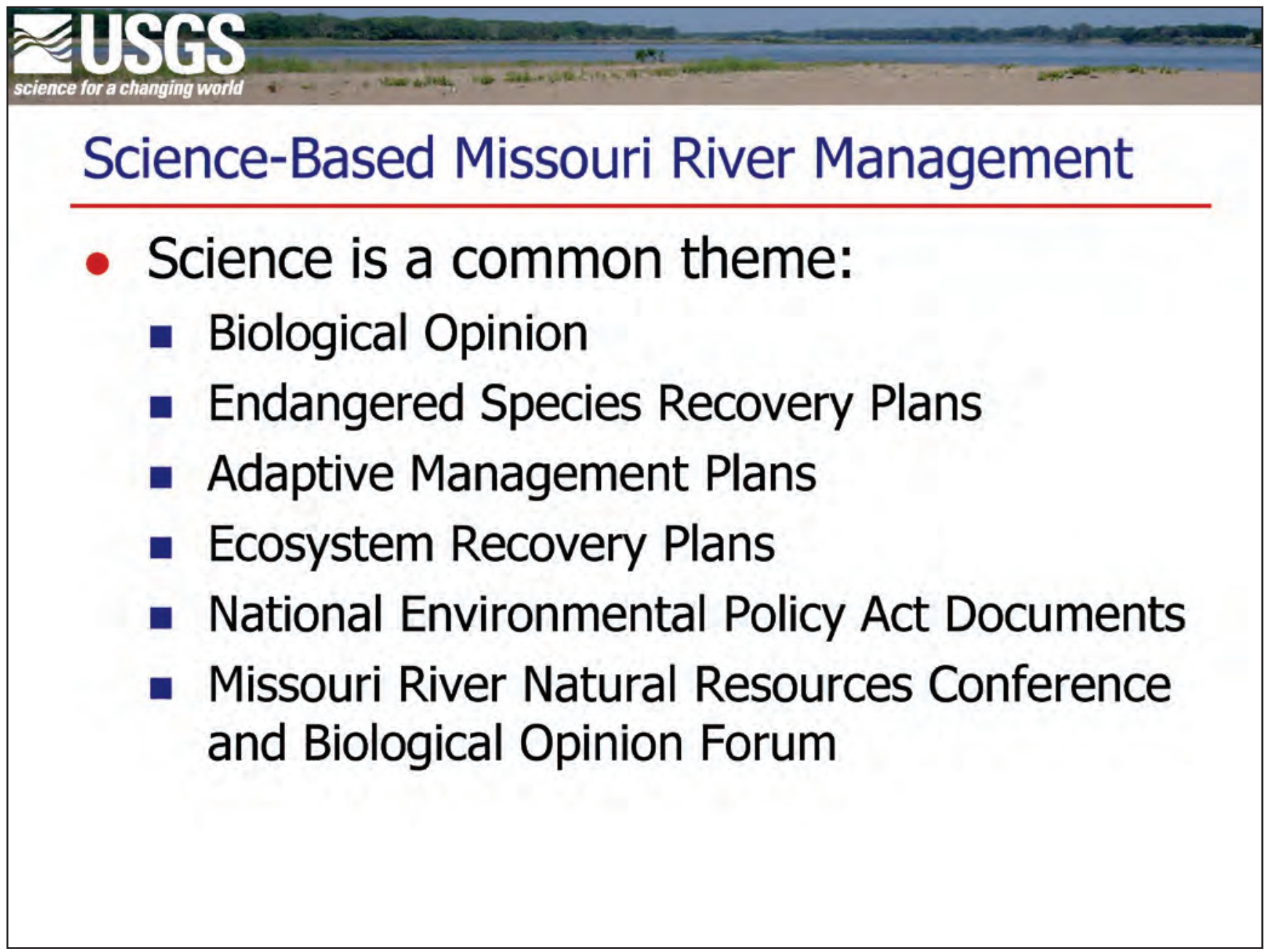

This presentation initiates a session on management of least terns and piping plovers, but it is really about science and how it is conducted in support of the many important decisions that are made while managing the Missouri River system. There are many documents and plans that guide how this system is managed including the Missouri River Biological Opinion, various recovery and management plans, the Missouri River Ecosystem Recovery Plan, National Environmental Policy Act documents, and others. Throughout these there is a recurring theme of importance of science in managing the system. In fact, the Missouri River Natural Resources Conference has a principal role of exchanging scientific information, which is a key expression of how important science is on the Missouri River. 


\section{Slide 4}

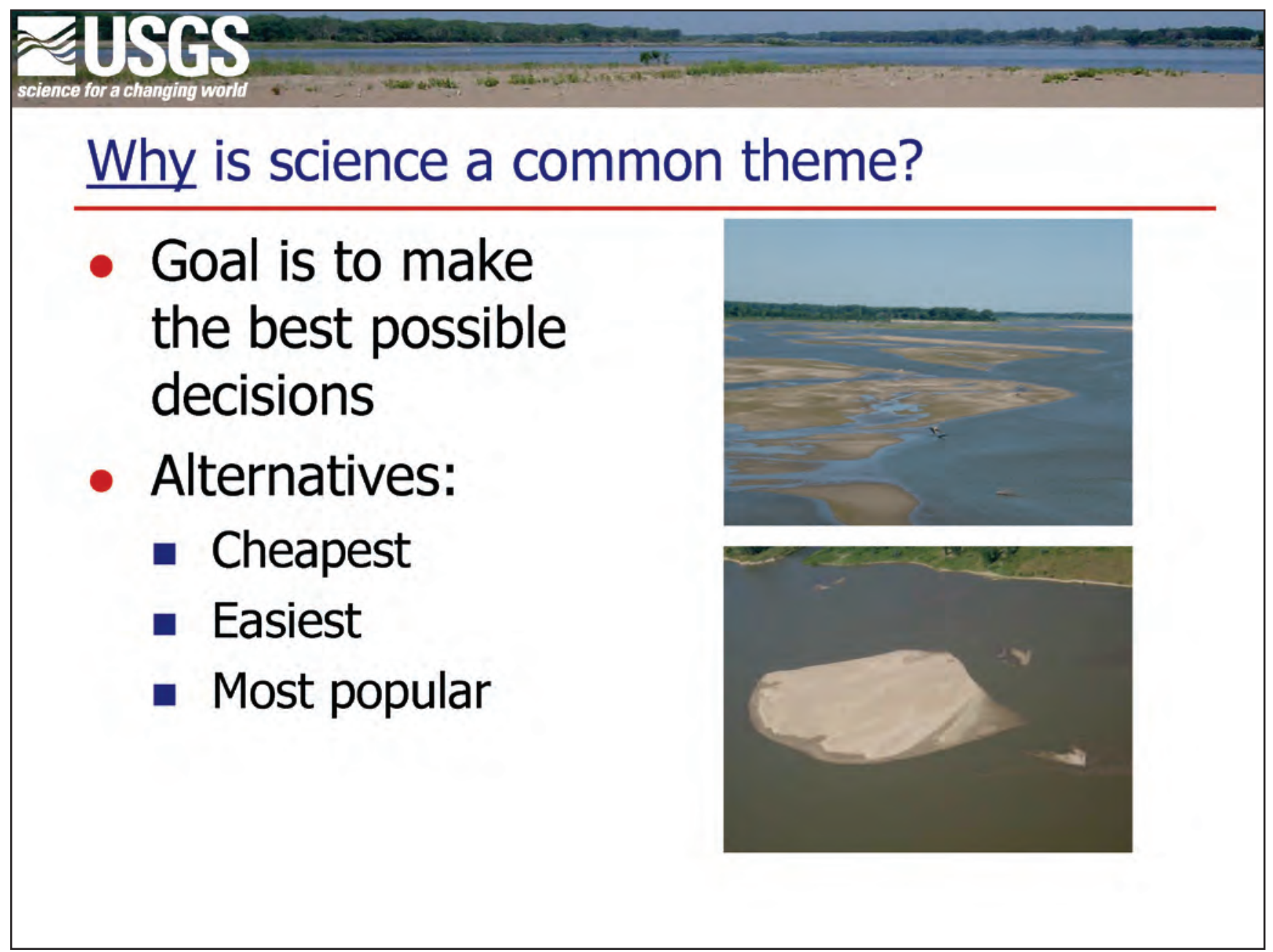

With science being such a common element in river management, we might ask a seemingly nonsensical question-why is science a common theme? The most obvious answer is that it is important to make the best decisions when faced with a choice, whether it is selecting a management action, making a decision about allocating resources, or reaching a conclusion about whether a management goal has been reached. It is not necessary to use science to make a decision. Alternative options would be to select the cheapest, easiest or most popular pathway forward. However, if ecological recovery of the river is the desired endpoint, then science is the most logical tool to support decisionmaking. 


\section{Slide 5}

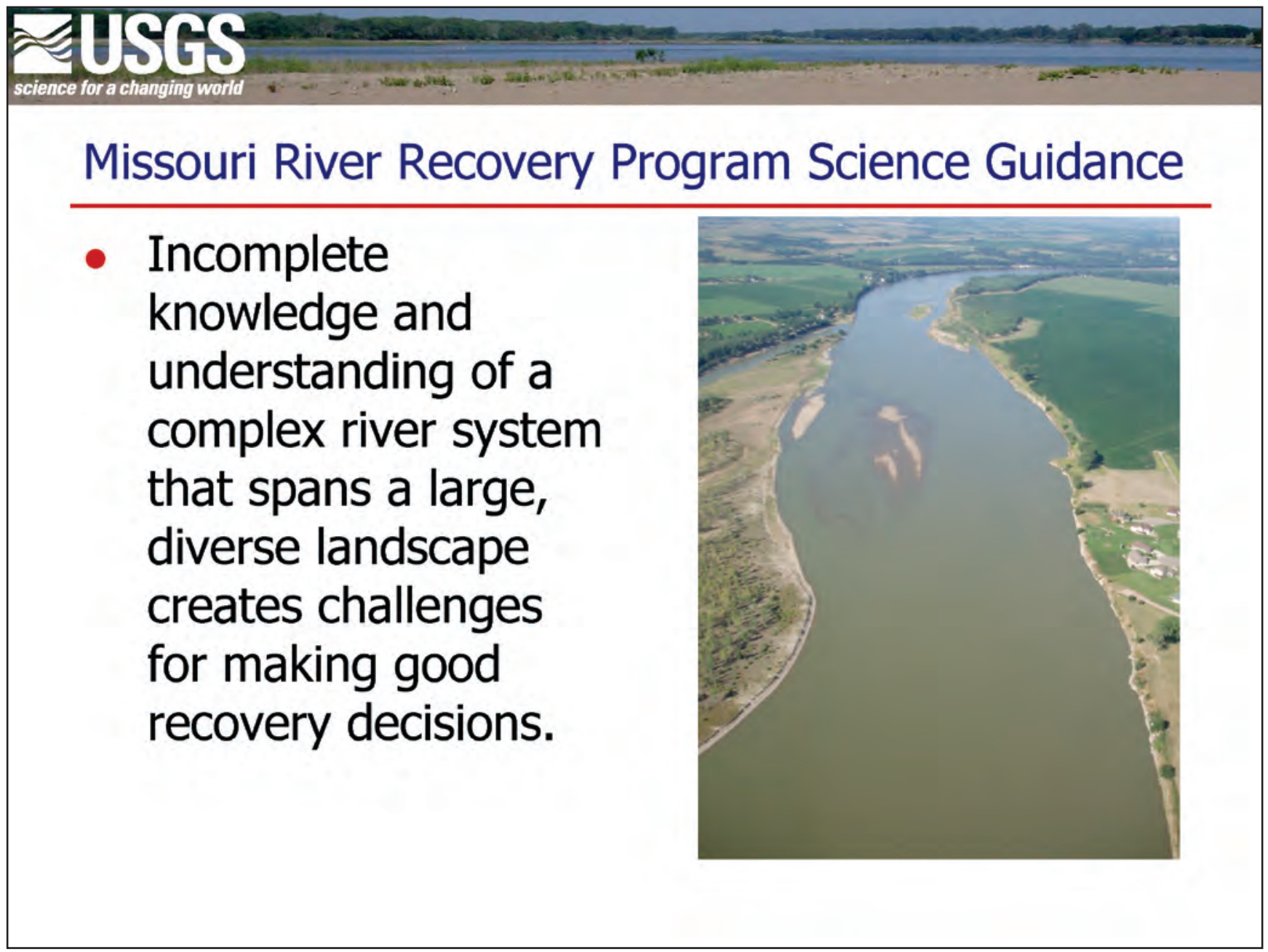

Looking more closely at the Missouri River Recovery Program, the importance of scientific information quickly becomes evident. The Program's science guidance prioritizes science by stating "Incomplete knowledge and understanding of this complex river system that spans a large, diverse landscape creates challenges for making good recovery decisions." This presentation will look at several components of science-based decisionmaking and reflect on how they are being implemented, specifically with reference to least terns and piping plovers.

The last four words in this guidance are a key reminder of the context for this discussion. Not only is it important to make good decisions, but it is important that they be focused on recovery of the river system and its sensitive species. 


\section{Slide 6}

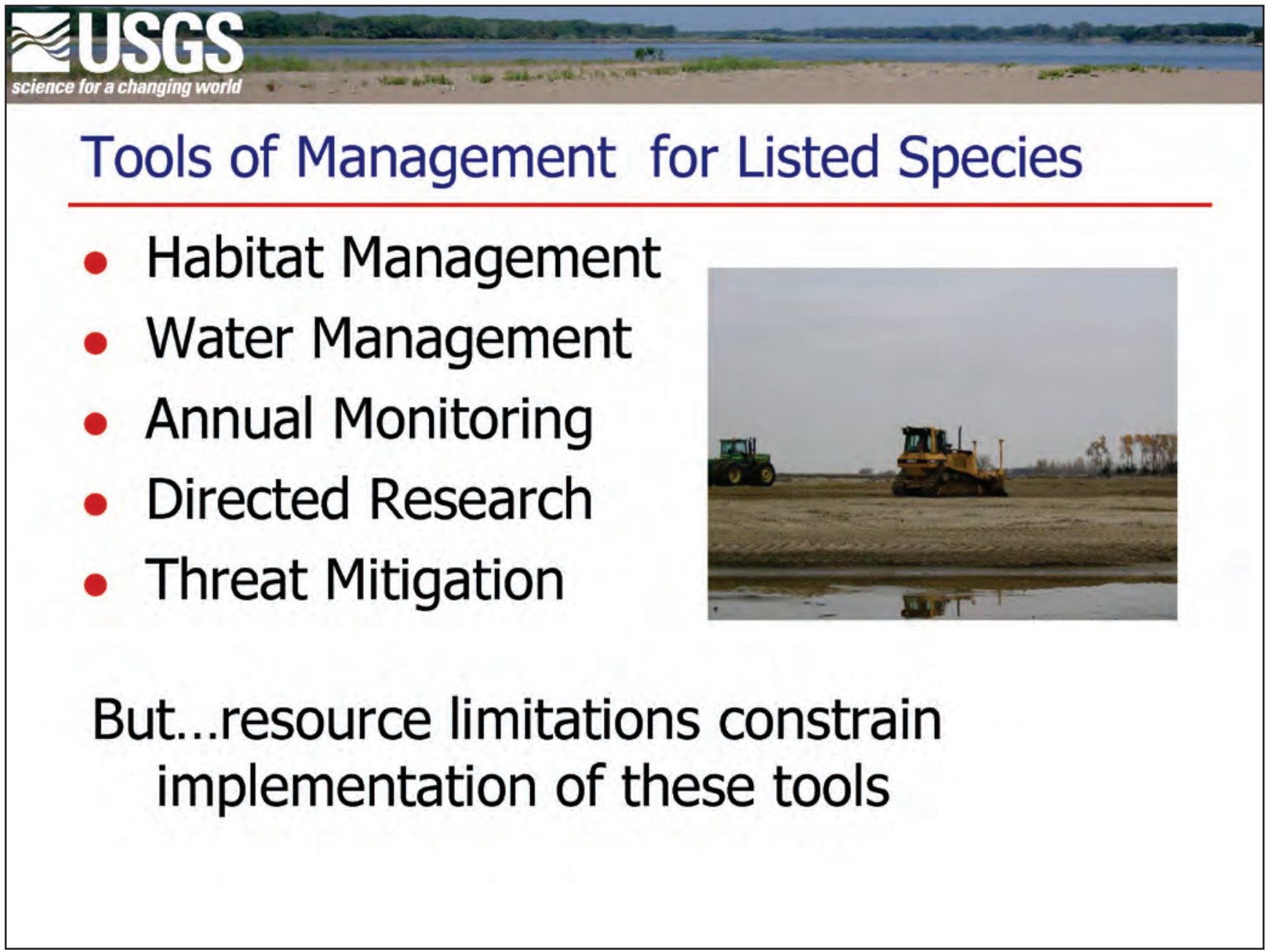

Many tools are used to implement the Missouri River Recovery Program guidance as it relates to threatened and endangered species on the Missouri River. These include habitat management (such as sandbar construction), water management (such as manipulation of dam releases to minimize flooding of nests), annual monitoring of habitat and productivity, directed research related to tern and plover biology, and mitigation of threats that may cause mortality or other negative effects. Each of these has its own unique set of decisions that go into implementation and influence ultimate outcomes. Each of these also generates some sort of response, which may be a biological response, a physical response, or, more likely, many complex responses. Additional challenges arising from these responses relate to whether or not they can be detected and properly interpreted, and whether the resulting information can be used appropriately to make subsequent decisions. However, as usual, there is a catch. Resources are limited, which constrains how and even if these tools are implemented. 


\section{Slide 7}

\begin{tabular}{l} 
Efficiency vs. Effectiveness \\
\hline - Efficiency - One data source informs \\
multiple decisions \\
- Effectiveness - Decisions are informed by \\
reliable knowledge \\
- Important tradeoff to consider because of: \\
- Ecological importance of Missouri River \\
- Recovery \\
- Lonservation status of key resources
\end{tabular}

Therefore, it becomes very important to consider the tradeoff between efficiency and effectiveness of data used to make decisions. Efficiency can be maximized by using a single data source to make multiple decisions, whereas effectiveness of a given decision can be maximized if the decision is based on scientifically valid, directly applicable information. This kind of information is also known as reliable knowledge. Ideally we'd like to be both efficient and effective, but it is rarely the case that a single type of data can inform a wide variety of decisions. Therefore, it becomes important to understand the data needs of each potential decision. This tradeoff between effectiveness and efficiency is especially important for the Missouri River system because of the ecological importance of recovery, the conservation status of key resources such as threatened and endangered species, and the limited resources available to collect data. 


\section{Slide 8}

What is Data?
"Data" implies information content with
respect to an objective (Anderson, 2001).
- Numbers are not always data.
- Lots of numbers (large sample size) does
not guarantee good data.
- Identifying the information content
requires understanding the objective.
Anderson, $D . R_{\text {., }}$ 2001, The need to get the basics right in wildlife field
studies: Wildife Society Bulletin, $v .29, p .1,294-1,297$.

To further understand this challenge, let us reflect a moment on what we mean by data. David Anderson wrote a paper in 2001 titled "The need to get the basics right in wildlife field studies", and in that paper he defined data as implying information content with respect to some objective. This way of thinking emphasizes a couple of important points. First, numbers are not always data. Numbers are only data when they are supported, collected, and interpreted in reference to an objective. Second is the sample size trap. Most of us believe more is better when it comes to numbers, but simply having lots and lots of numbers does not guarantee good data. If the fundamentals, such as the guiding objectives or the sampling design, are flawed, then no quantity of numbers can produce good data. Third is the underlying objective that motivated data collection in the first place. If the objective is not clearly stated and well understood, then there is a reduced likelihood the data will be, which has subsequent implications for whether decisionmaking is based on the best information. 


\section{Slide 9}

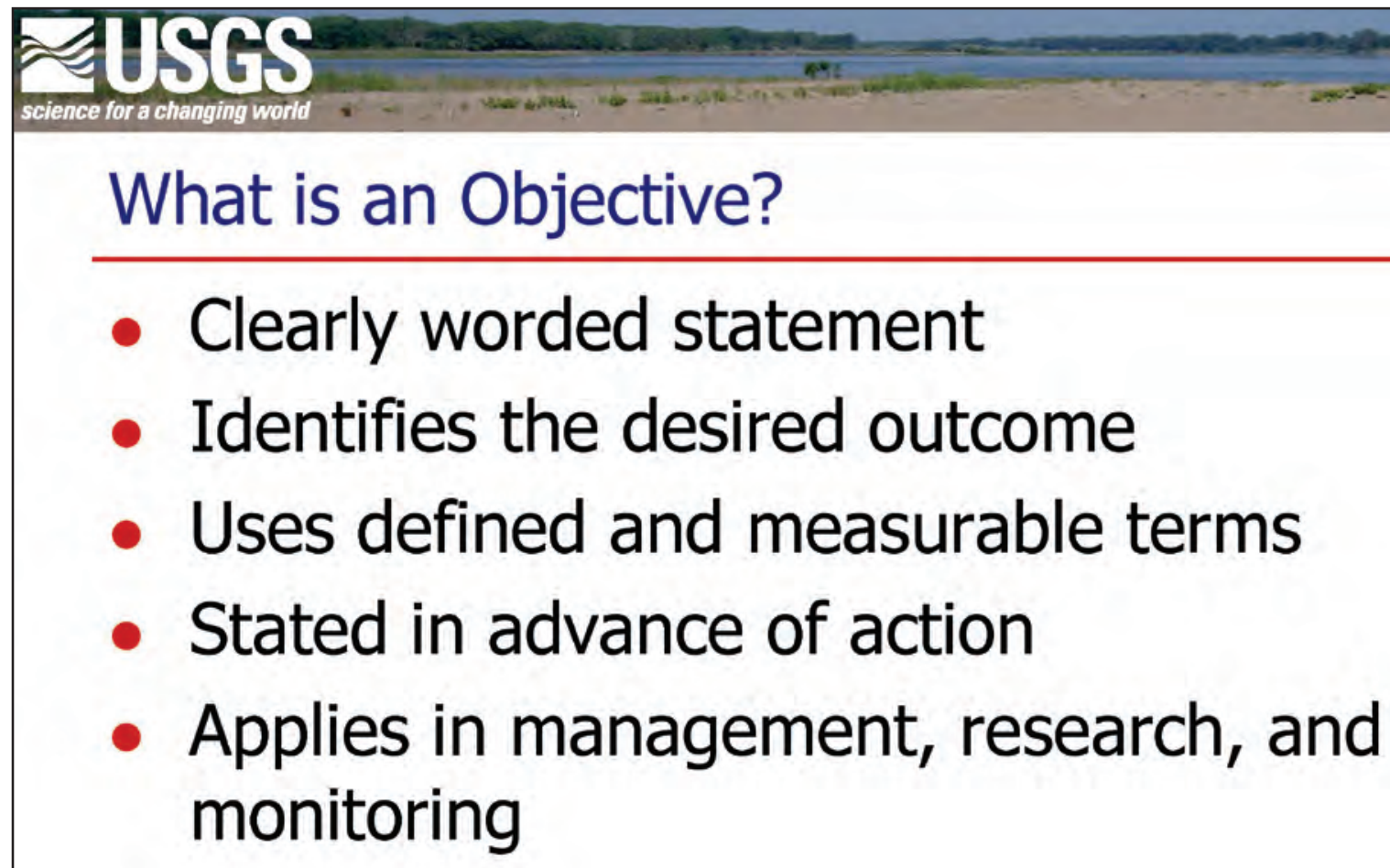

Based on that definition, data and their supporting objective are inseparable. Therefore, it is also important to understand what an objective is. An objective is a clearly worded statement that identifies a desired outcome in measurable terms that is stated in advance of an action. The context presented in this report is relevant mostly to tern and plover monitoring, but these same ideas apply in conducting research and in implementing management actions. 


\section{Slide 10}

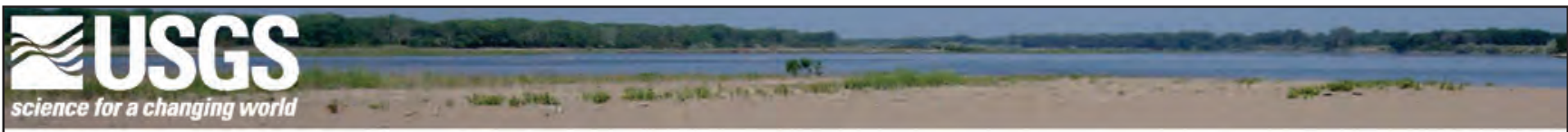

\section{Example - Piping Plovers}

\section{Objective A: "Determine abundance of piping plovers." \\ Objective B: "Estimate annual breeding population of piping plovers on segment $X$ of the Missouri River."}

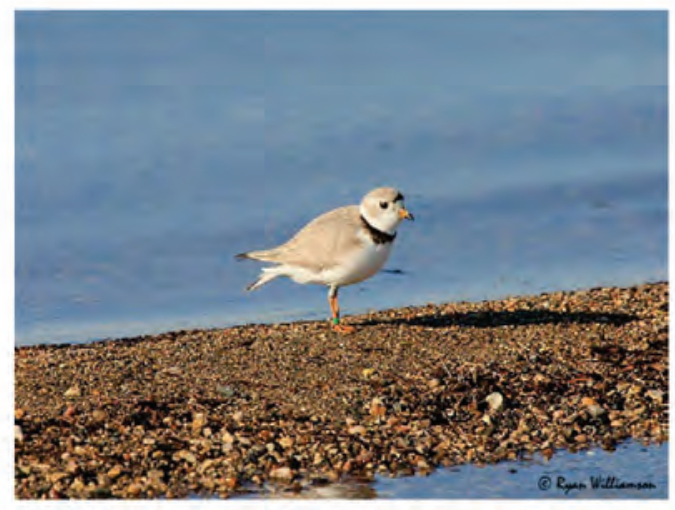

To illustrate these concepts, consider an information need about abundance of piping plovers. Here are two potential ways to phrase an objective to drive data collection on piping plover abundance. Objective A recognizes the need for information on abundance of piping plovers, but it's very general and leaves a lot of uncertainties. Objective B, however, provides a lot more information. The very first word is important - it tells us an estimate is needed, as opposed to a complete census of piping plovers. The second word is also important_-it tells us these estimates are needed annually. Next, Objective B says that breeding population will be measured. This is much more specific about information needs than the word "abundance" in Objective A. Finally, Objective B states the spatial scale at which the estimate is needed - segment X of the Missouri River. 


\section{Slide 11}
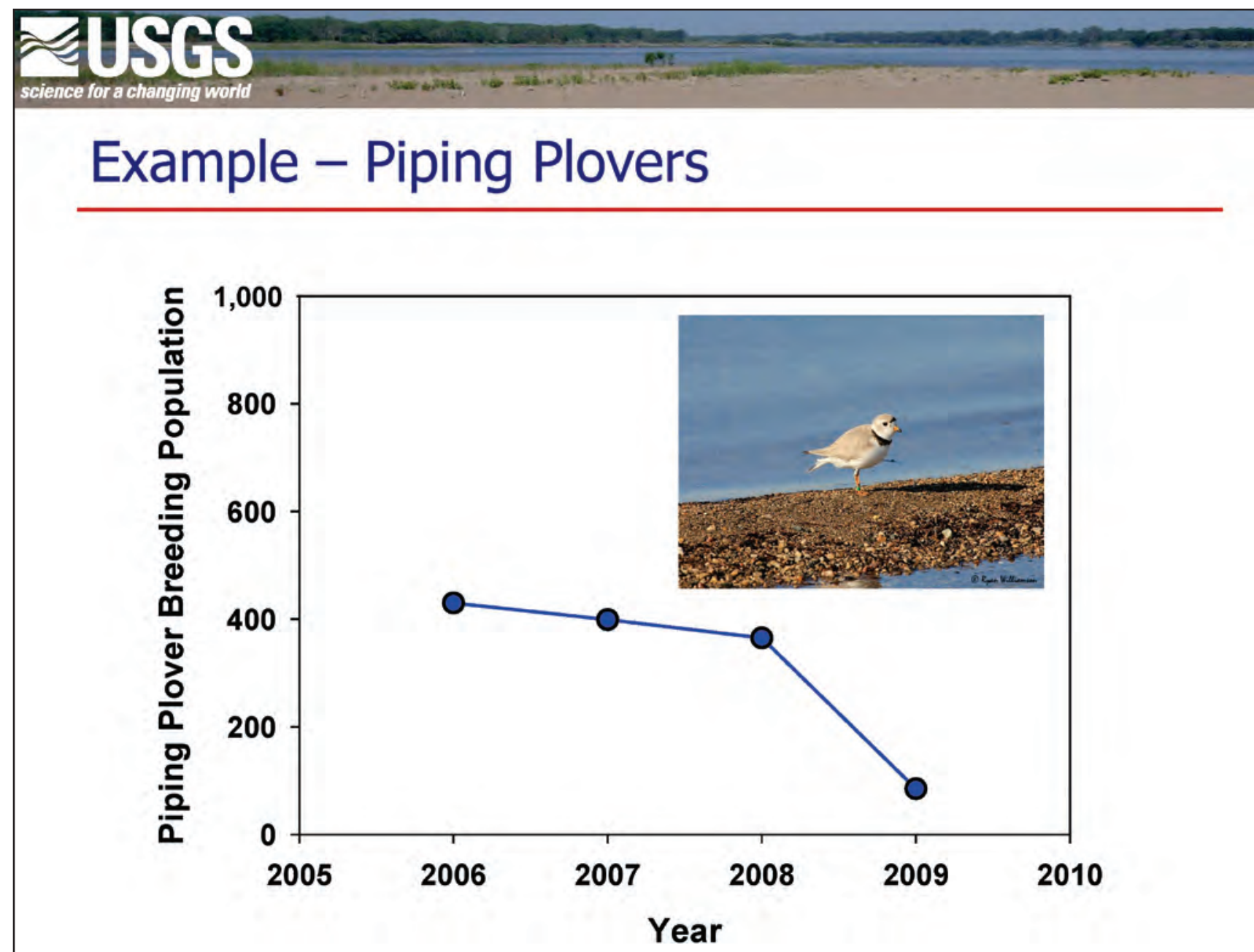

The importance of clearly stated objectives can be seen by examining some data collected on breeding population of piping plovers on the Missouri River. This graph shows estimates of the breeding population for each of 4 years on a segment of the river. This graph might prompt a couple of management-relevant questions, such as "what was the breeding population of plovers in 2008?" It is simple to read a value off the graph and make management decisions based on that information. One also might be interested in the trend in breeding population between 2006 and 2009 and feel pretty certain it declined based on this graph. 


\section{Slide 12}

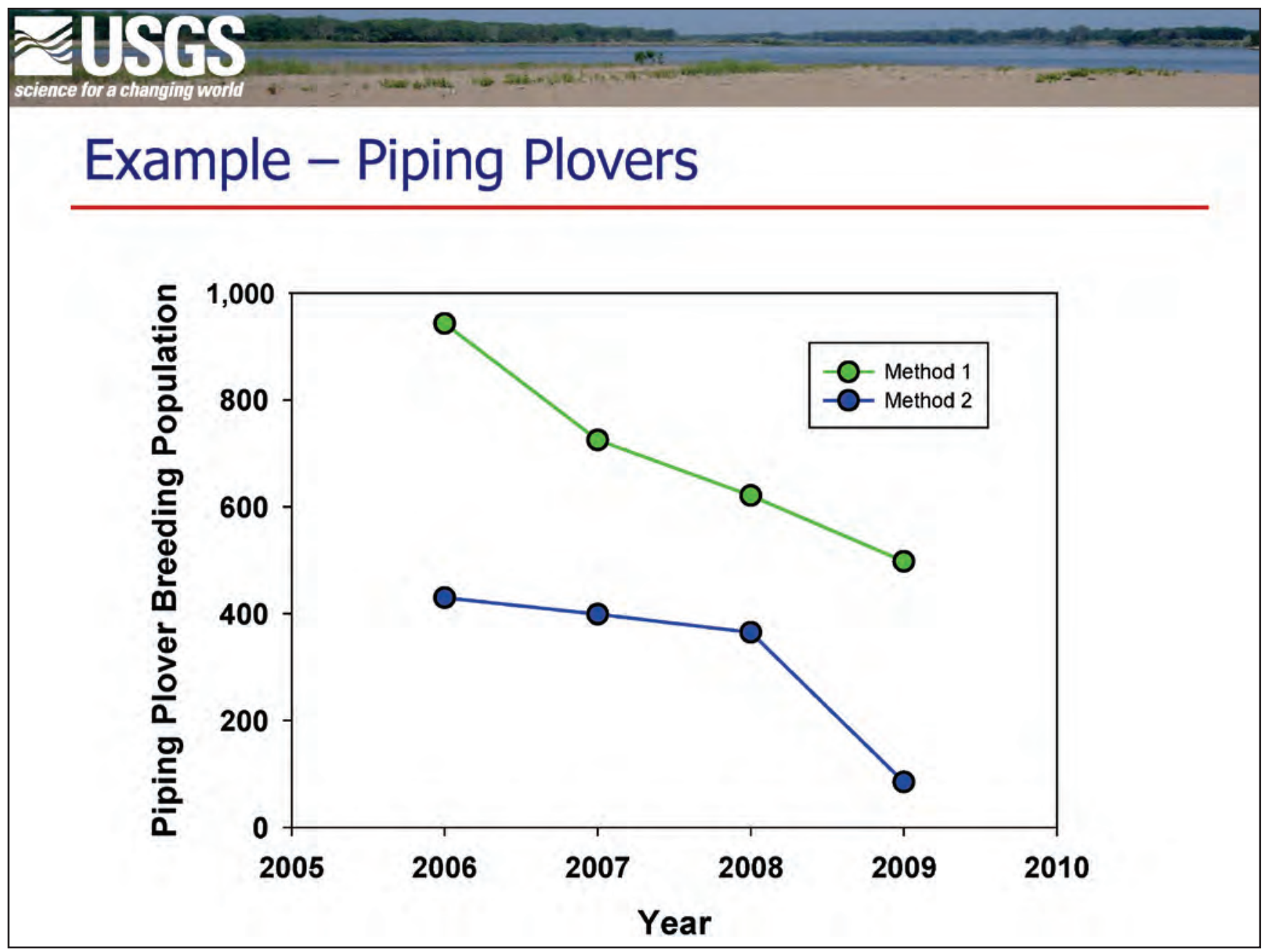

However, imagine what would happen if a second measure of breeding population from the exact same area was available, but it was measured using different methods. Now that question about the breeding population in 2008 becomes a lot less certain, because there are two very different estimates - one approximately 375 birds, and the other approximately 625 birds. Now it becomes really important to understand the differences in how these two datasets were collected and what objectives motivated collection of the data. Both datasets illustrate similar patterns of declining plover populations, but very different ones about the true number of breeding birds. Thus, it should be evident that simply labeling the response variable (in this case, breeding population) is insufficient to interpret a dataset.

In the prior slide, when only one dataset was presented, it was easy to rapidly make several conclusions about both trends and absolute abundance of breeding birds. In practice it is very rare that two complementary datasets are available to force thinking about how and why data were collected, but understanding the motivating objectives for a dataset should always be a priority when interpreting data. 


\section{Slide 13}

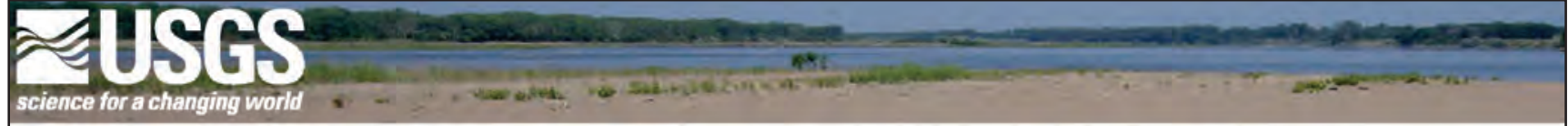 \\ Prospective vs. Retrospective Questions \\ - Prospective: \\ - Stated before data collection \\ - Enables sampling design to address predictions and competing hypotheses \\ - Strong inference and reliable knowledge \\ - Retrospective: \\ - Stated after data are in hand \\ - May be loosely related to question that motivated data collection \\ - Inference may be weaker, knowledge less reliable}

It is often tempting, and sometimes useful, to pose questions after a dataset has been collected, which might be labeled as a retrospective question. A prospective question is one that is stated in clear and measurable terms in advance of data collection, enabling a sampling design to assess predictions and competing hypotheses. In contrast, a retrospective objective is one stated after the data are already in hand that may be only loosely related to the original motivating objective. This can lead to inferences that are weaker and knowledge that is less reliable.

Does this mean that retrospective questions should not be asked and cannot be answered? No, but it does mean that caution is needed to ensure that retrospective questions remain aligned with the original objectives and design principles that motivated the data collection. 


\section{Slide 14}

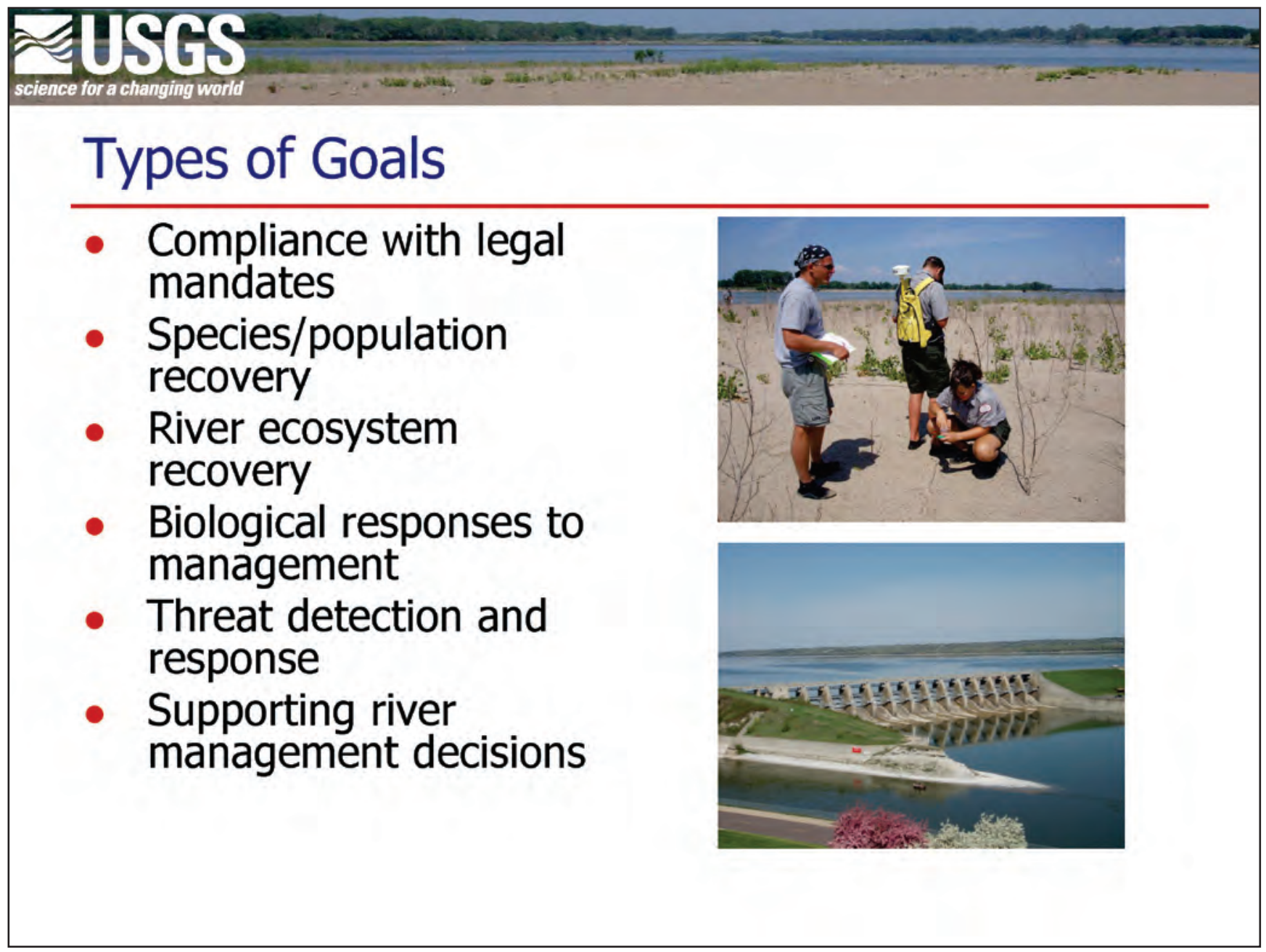

Several different types of objectives are relevant to monitoring terns and plovers on the Missouri River. Each of these implies a different response variable that may be measured at a different scale.

Legal mandates include things like the Biological Opinion, which has very familiar goals for fledge ratios, suggesting measures of fledglings and breeding population are needed for the river system as a whole.

Species and population recovery plans for terns and plovers provide breeding population targets for the midcontinent population of both species.

Ecosystem recovery efforts such as the Missouri River Ecosystem Recovery Program are looking at system-wide targets for populations and productivity of terns and plovers. These kinds of targets will be used to evaluate success of ecosystem restoration, and they're different in spatial scale than the targets used in recovery plans or the Biological Opinion.

There are many management actions made to benefit terns and plovers, such as building sandbars, managing vegetation, caging nests, and managing predation. Each of these is taken at a different spatial scale and has a unique desired outcome, and these ought to be taken into account when setting objectives for monitoring.

Detecting and responding to threats is another objective that might require localized supporting data that matches the spatial extent of the threat.

And finally, river management decisions, such as manipulating flow rates to avoid loss of nests, might require information about everything that is happening at a given band of elevations that are affected by a water management decision. 


\section{Slide 15}

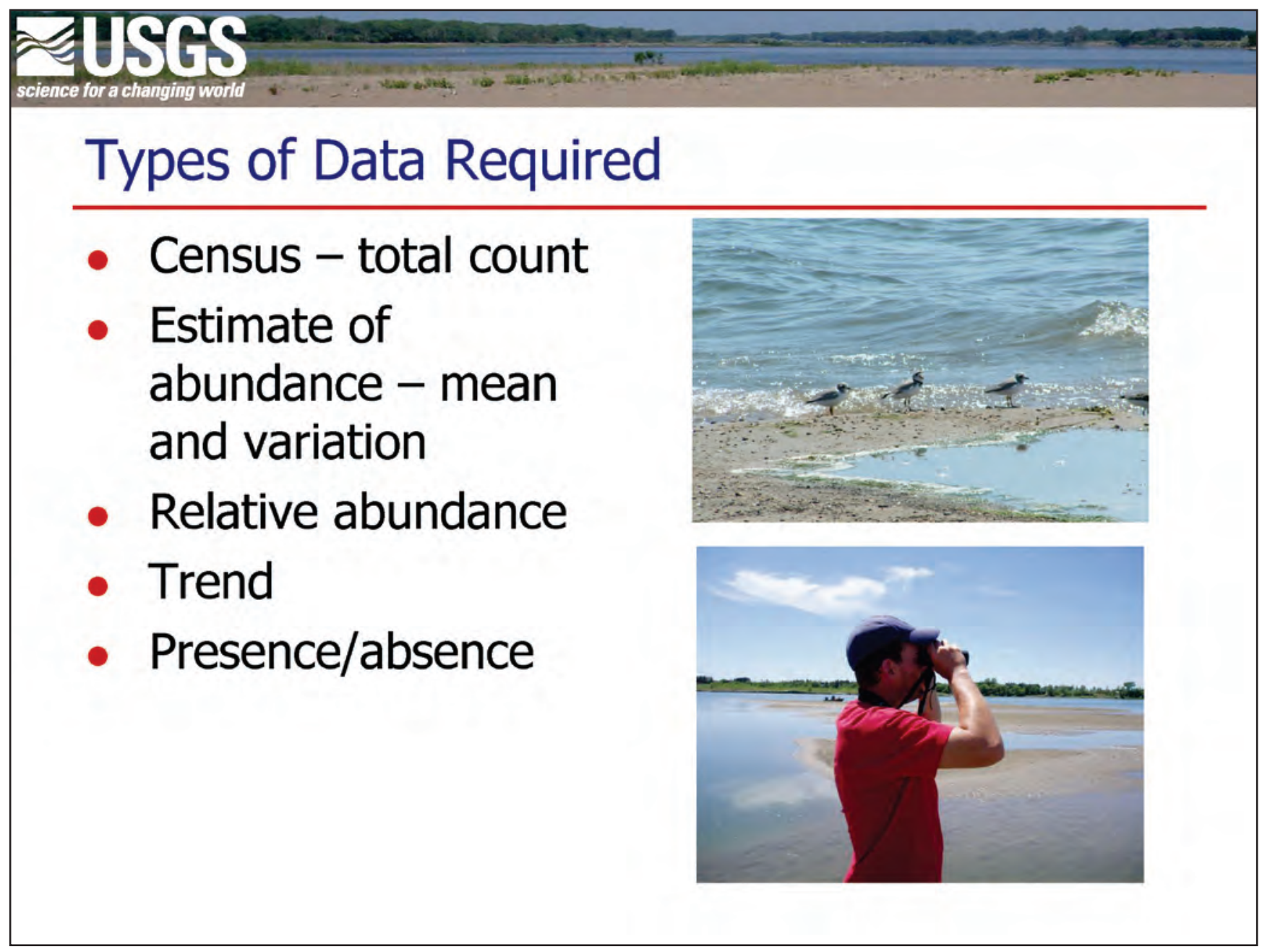

As diverse as these types of objectives are, the types of data needed to address them are equally diverse. Some objectives might require a census or a total count of individuals, whereas others may only require an estimate of mean and variation in abundance. It might not be necessary to know the absolute value of abundance, but just the relative abundance of individuals between two areas or two habitat types. It might not even be necessary to measure abundance at all as long as it is possible to detect trends, and it might not be necessary to quantify trends as long as one can determine where individuals are present and where they are absent. There are profound differences in how these different types of data are collected, and choosing the correct data type is linked intimately with the supporting objective. 


\section{Slide 16}

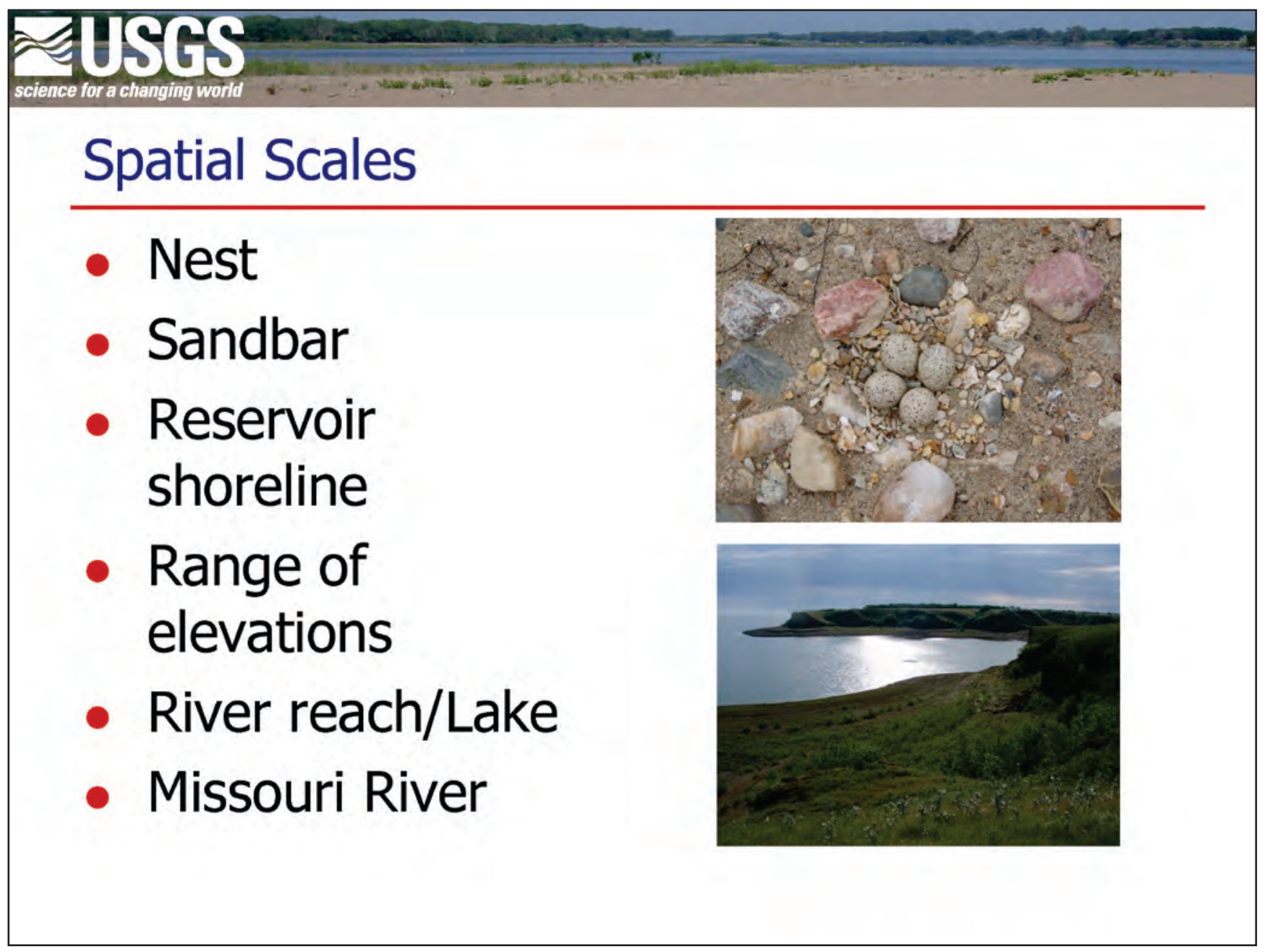

Likewise, there are many spatial scales at which data can be collected, ranging from very fine scales like nests or sandbars, to very coarse scales such as river reaches, lakes, or the entire Missouri River system. It might be necessary to sample in between these extremes, such as at the scale of a certain management action or within a certain range of elevations. Again, there are profound differences in how data are collected at each of these scales, and a clearly articulated objective will identify the proper spatial scale to ensure resulting data are appropriate for inference at the correct scale and informing the decision at hand. 


\section{Slide 17}

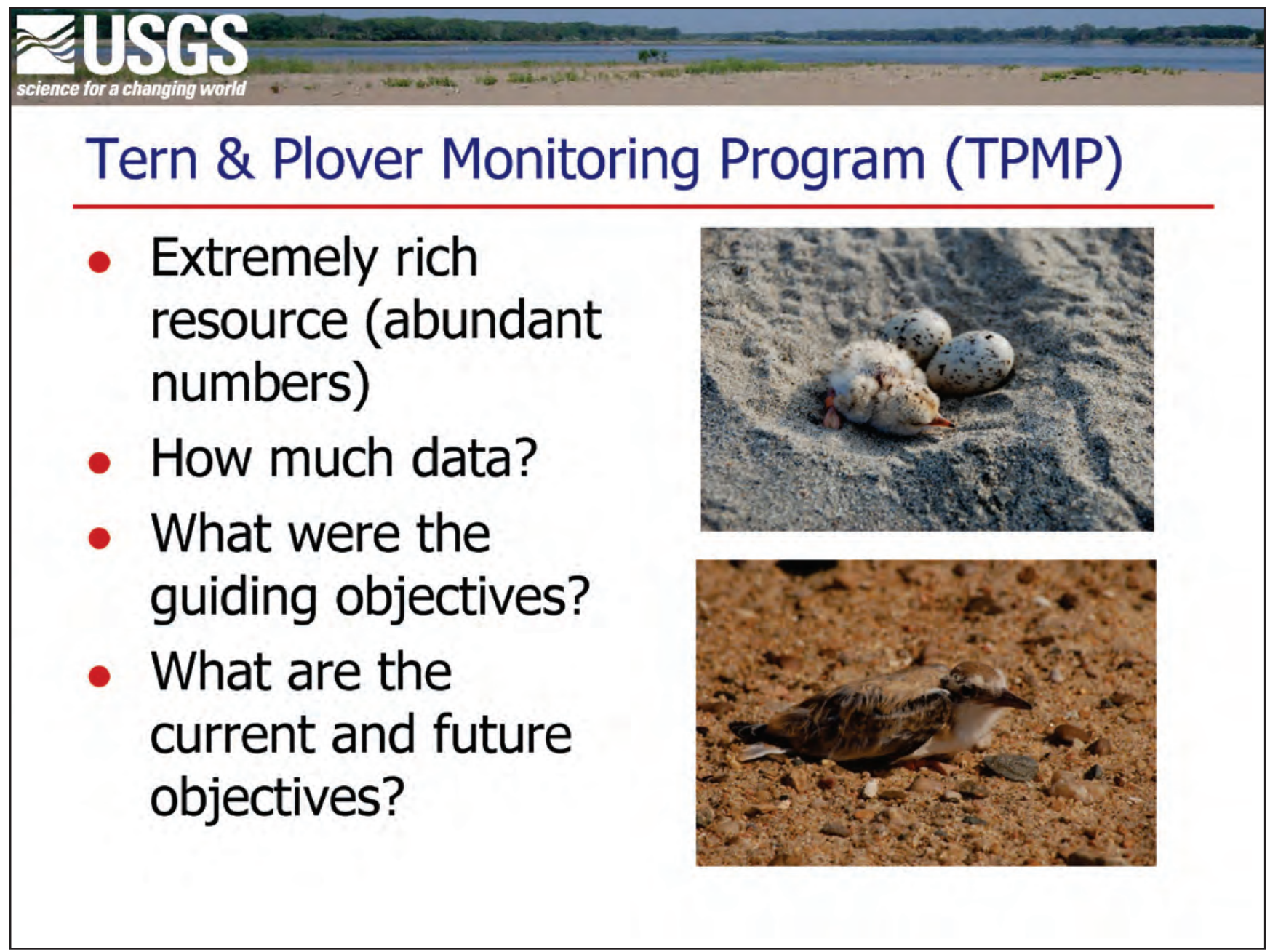

So how does all of this apply to the tern and plover monitoring program on the Missouri River? The program is clearly an extremely rich resource that has produced an abundance of numbers, but one of the uncertainties is how much "data" is contained in those numbers. Teasing the data out of the monitoring program requires an understanding of the objectives that have guided the program since its inception. Likewise, making adjustments to the program for the future requires an understanding of current and future objectives. 


\section{Slide 18}

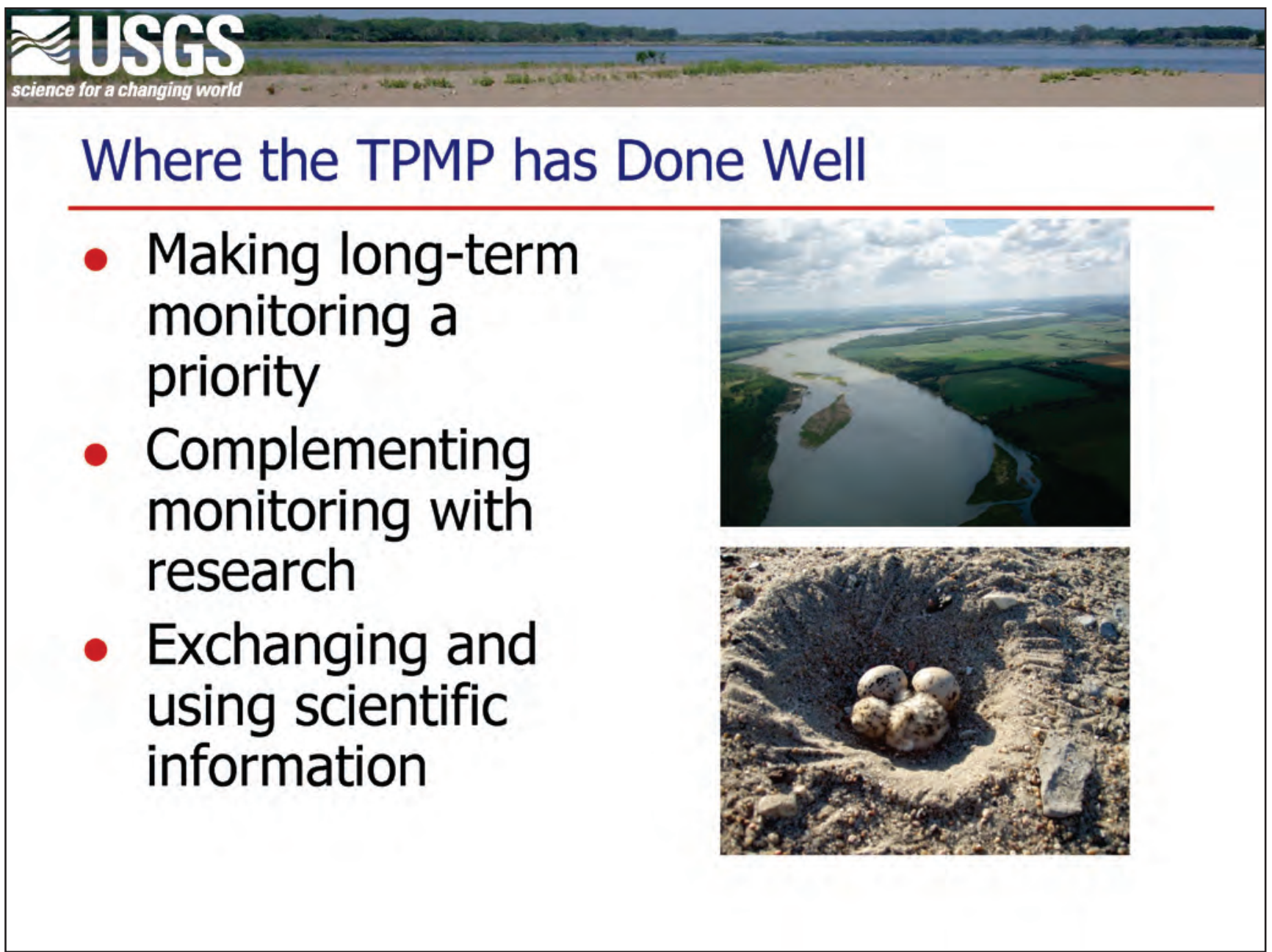

Despite these uncertainties, there are several areas where the monitoring program has done well. First, the program has assembled unique datasets on Federally listed species through its prioritization of long-term monitoring. Second, by complementing long-term monitoring with directed research, the program has shown that diverse sources of scientific information are important in decisionmaking. Third, the program has emphasized exchange and use of scientific information as a means to promote recovery of the river system. 


\section{Slide 19}

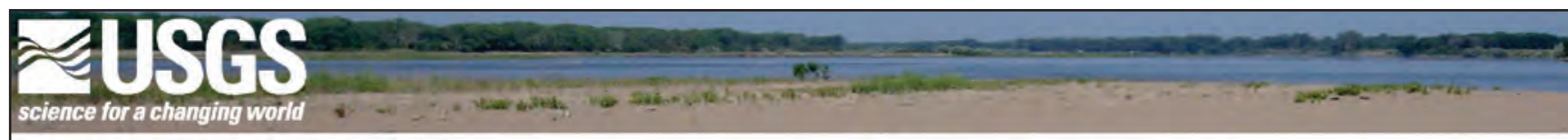

\section{Future of Tern \& Plover Monitoring}

- Collecting and analyzing data will be the easy part

- A necessary (and difficult) precursor is deciding what data should be collected and why they should be collected.

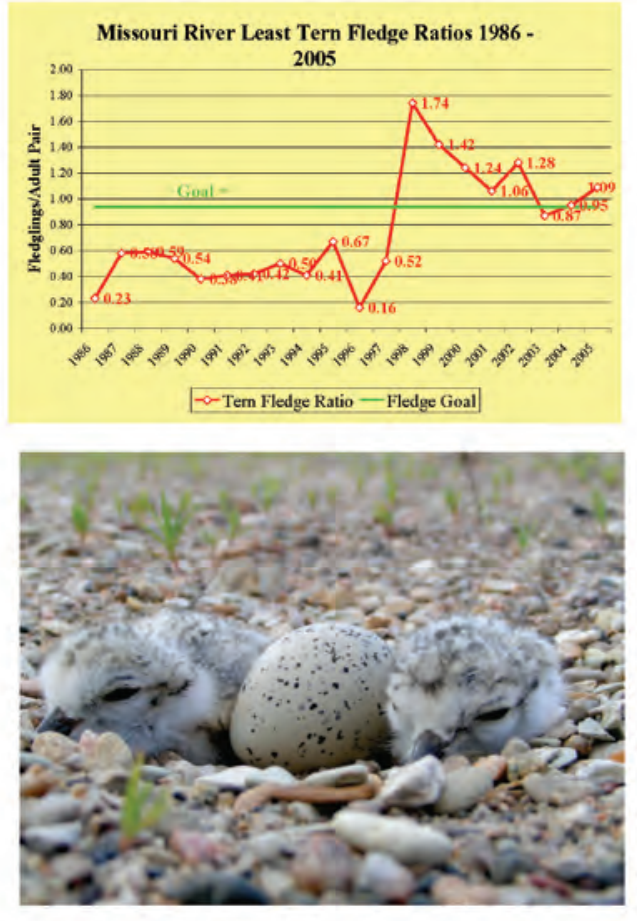

There has been much discussion recently about future adjustments to the monitoring program, and many discussions focused on how data are collected. In the future we will probably find that collecting and analyzing data will be the easy part. However, decisions about what data should be collected and why will likely be a necessary and much more difficult precursor. 


\section{Slide 20}

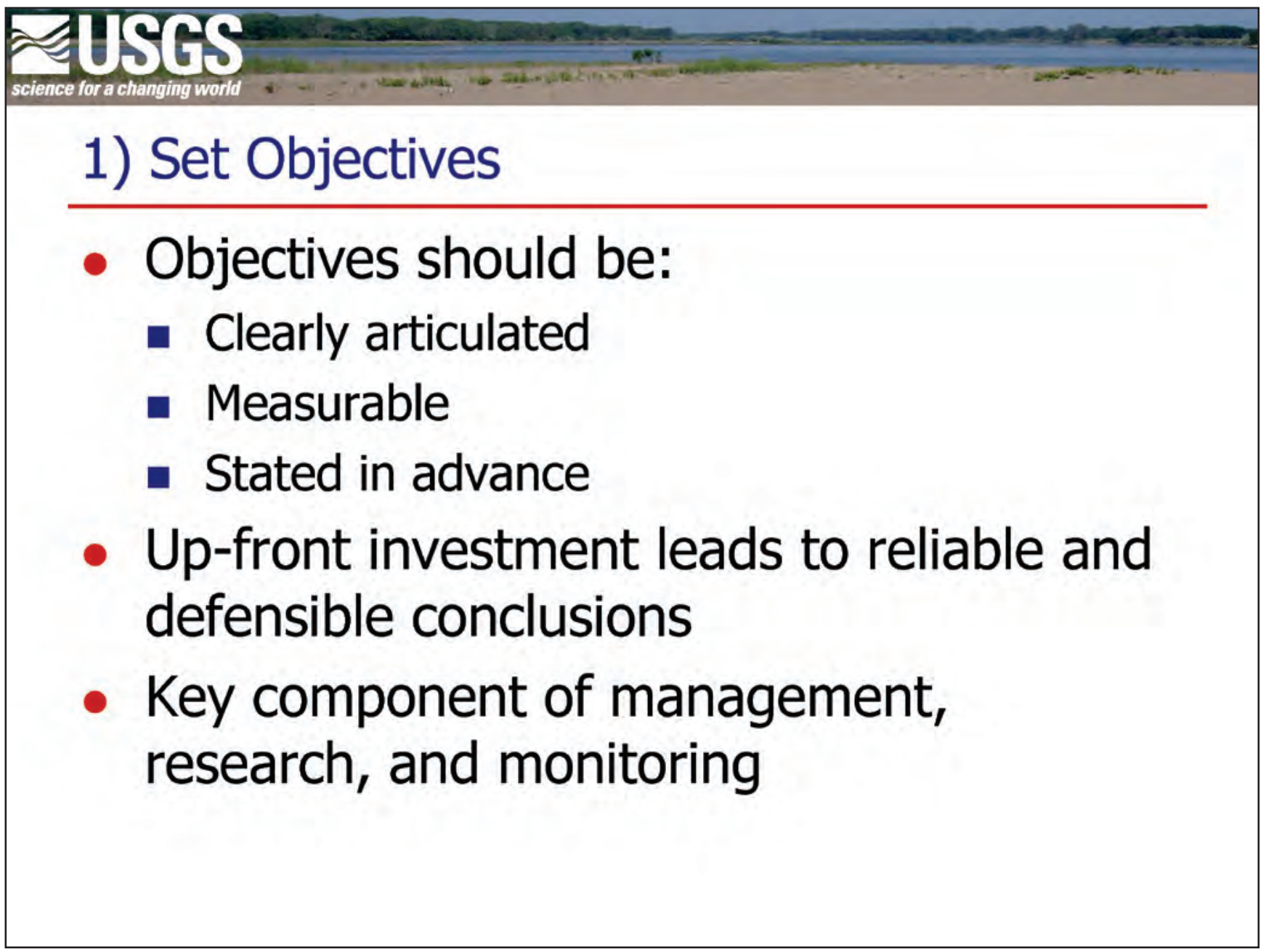

The concepts illustrated in this presentation can be summarized in five points that might be considered as the tern and plover monitoring program moves forward. First, take actions with a purpose by setting objectives that are clearly articulated, measurable, and stated in advance. This up-front investment will lead to reliable and defensible conclusions and should be a key component of management, research, and monitoring. 


\section{Slide 21}

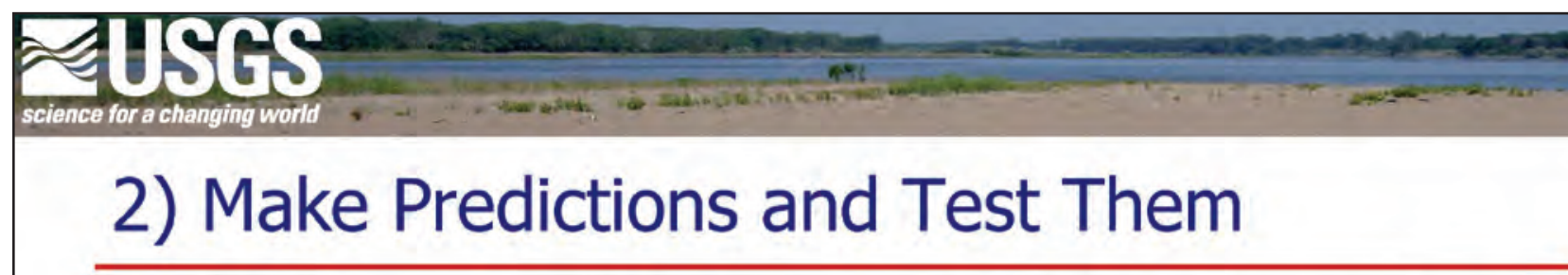

- Outcomes of a management action often can be anticipated

- Identify two or more possible outcomes and the associated biological metrics

- Design implementation and monitoring to evaluate competing hypotheses

Second, is to make predictions and test them. Often it is the case that the likely outcome of a management action can be anticipated. If two or more potential outcomes can be articulated along with the associated biological metrics that would be associated with each outcome, then implementation and monitoring approaches could be readily designed to distinguish among the outcomes and support or refute these predictions. 


\section{Slide 22}

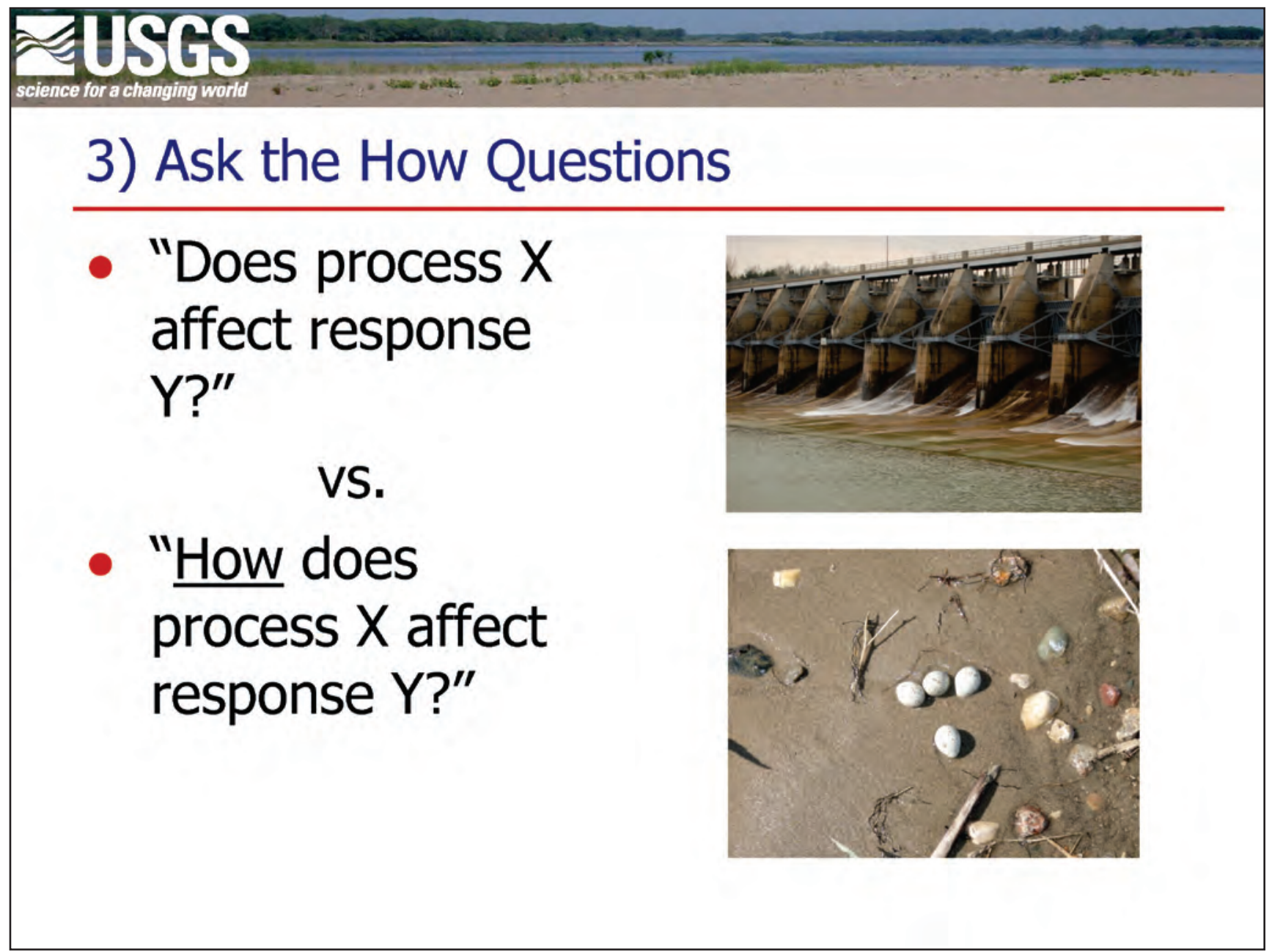

Third, is asking "how" questions. Often a very simple question, such as "Does process X affect response Y?" has a very simple but not very interesting answer- "Yes, it does." It is far more interesting and relevant to management if the question "How does process X affect response Y?" is asked and the study design and data collection are approached accordingly. 


\section{Slide 23}

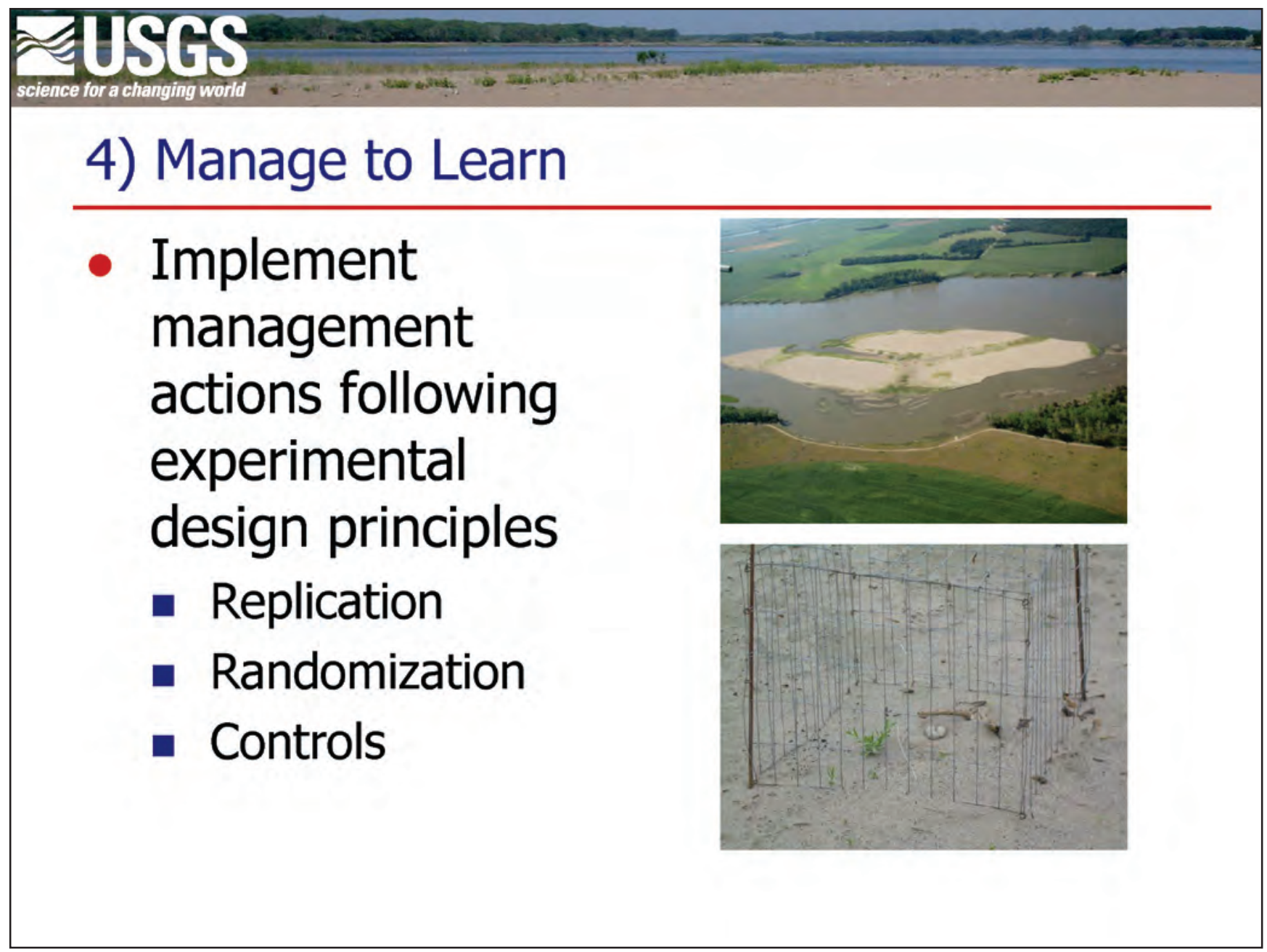

Fourth, the program could learn more by implementing management practices in accordance with experimental design principles, such as replication, randomization, and experimental controls. There are several examples where the program already has taken these steps and many more examples where learning could be enhanced dramatically by subtle, but very important adjustments to standard practices. 


\section{Slide 24}

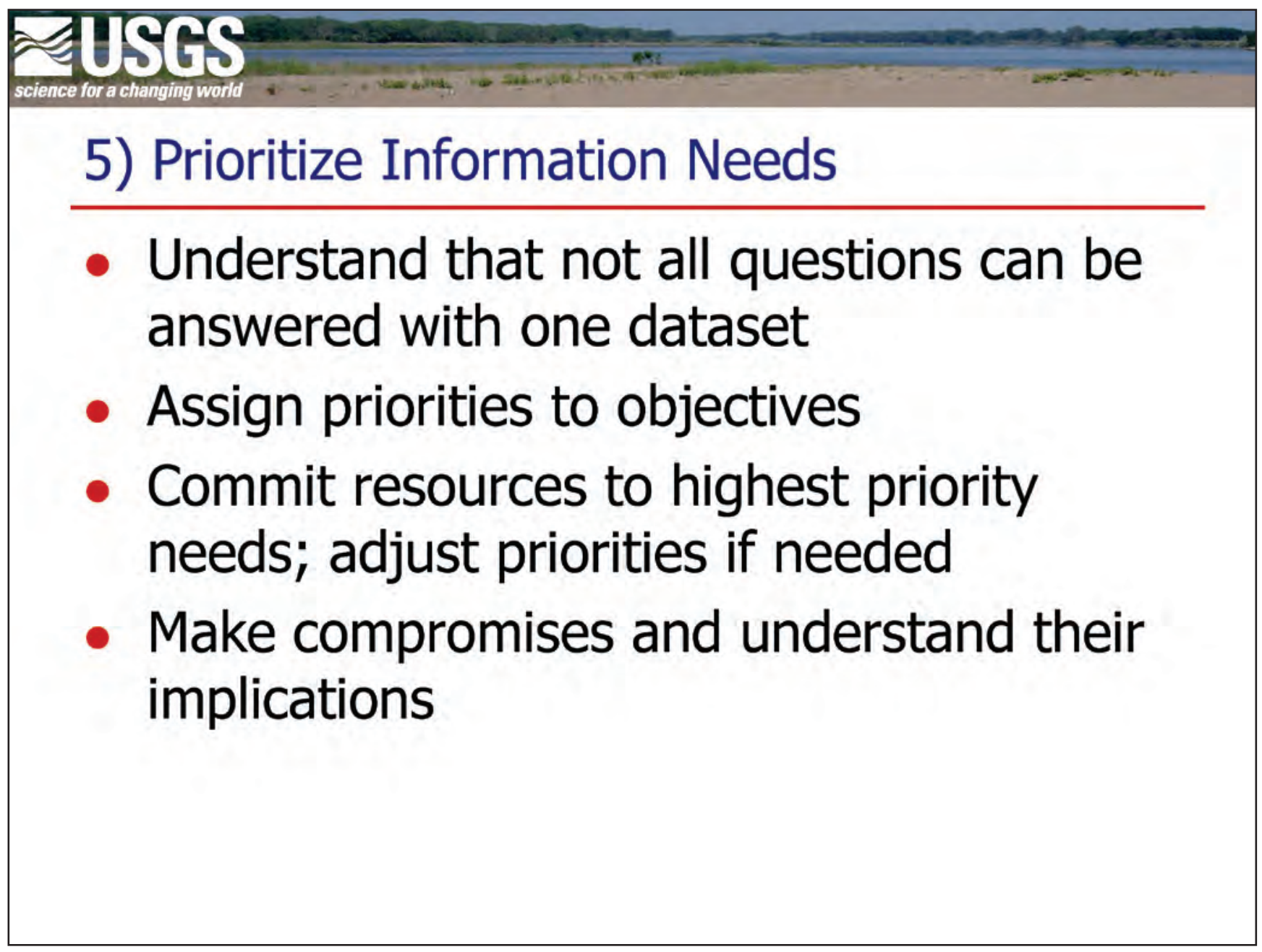

The final, and perhaps most important point, is prioritizing information needs. It is important to understand that not all questions can be answered with one dataset, but if objectives are prioritized and resources are committed accordingly, the greatest chance of meeting the most important needs occurs. It may be that the highest priority objective cannot be achieved because it is too expensive or beyond the recovery program's means, which would require priorities to be adjusted, compromises be made, and the implications of those changes be understood. 


\section{Slide 25}

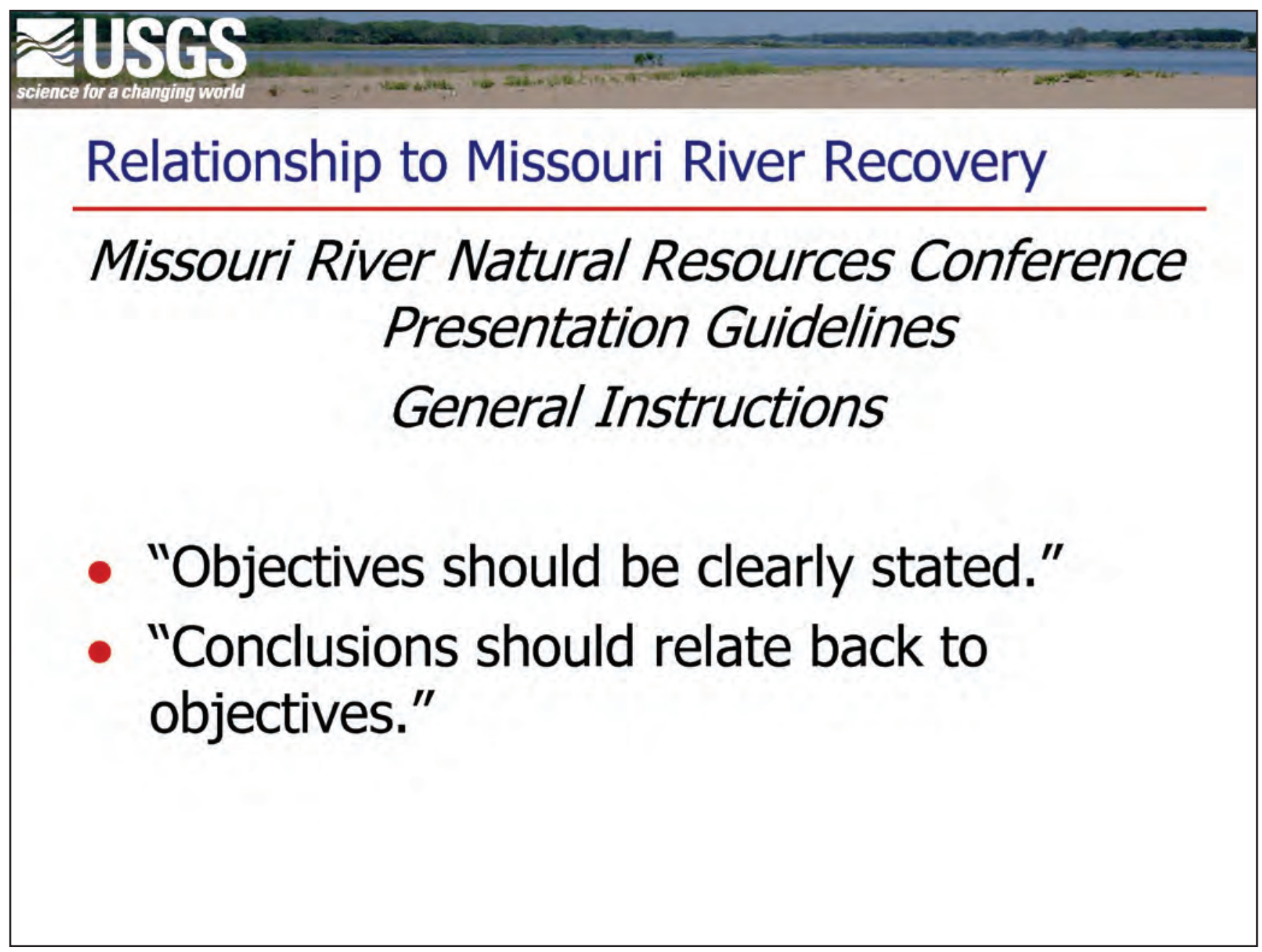

The guidelines for presentations at the Missouri River Natural Resources Conference asked authors to show how results were related to Missouri River Recovery. The instructions to presenters contained two statements that were very interesting, very encouraging, and very relevant not only to how science is being presented in this venue, but also to the actions to be taken when attendees leave the conference on Friday-Objectives should be clearly stated, and conclusions should relate back to objectives. This simple and concise statement is an excellent summary of the important points in this presentation. 
Publishing support provided by:

Rolla Publishing Service Centers

For additional information concerning this publication, contact: Director, USGS Northern Prairie Wildlife Research Center 8711 37th Street SE

Jamestown, ND 58401

(701) 253-5566

Or visit the Northern Prairie Wildlife Research Center Web site at: http://www.npwrc.usgs.gov 


